\title{
Barriers to accrue to clinical trials and possible solutions
}

\author{
Z E Winters ${ }^{*}, 1$, C Griffin ${ }^{2}$, R Horne ${ }^{3}$, N Bidad ${ }^{3}$ and P McCulloch ${ }^{4}$ \\ ${ }^{1}$ Breast Cancer Surgery Patient Reported and Clinical Outcomes Research Group, School of Clinical Sciences, University of Bristol \\ and North Bristol NHS Trust, Bristol, UK; ${ }^{2}$ The Institute of Cancer Research Clinical Trials and Statistics Unit (ICR-CTSU), Division of \\ Clinical Studies, Institute of Cancer Research, London, UK; ${ }^{3}$ Centre for Behavioural Medicine, UCL School of Pharmacy, \\ Department of Practice and Policy, London, UK and ${ }^{4}$ The Nuffield Department of Surgical Sciences (NDS), John Radcliffe Hospital, \\ Oxford, UK
}

A systematic review of worldwide phase 3 trials over 9 years showed that a third of all trials close early due to poor accrual (Schroen et al, 2012). The QUEST (Quality of Life after mastectomy and breast reconstruction) feasibility phase 3 trials (Cancer Research UK feasibility funded; CRUK/08/027) were two parallel randomised studies open across 15 UK centres that aimed to determine the optimal types and timings of latissimus dorsi (LD) back flap breast reconstruction using clinical and patientreported outcomes (Cancer Research UK, 2011). Systematic reviews had shown no reliable valid evidence addressing this question (Winters et al, 2010). Conceivably, the type of breast reconstruction surgery and its morbidities may affect women's health-related quality of life (HRQL) and satisfaction with outcomes. There is some evidence for this in both a prospective cohort study and the first UK National Mastectomy and Breast Reconstruction (NMBR) audit (The NHS Information Centre Clinical Effectiveness Unit at the Royal College of Surgeons, 2011; Winters et al, 2013).

The QUEST feasibility trials were pragmatic in design, with study entry determined by a pre-operative assessment of the requirement for post-mastectomy radiotherapy (PMRT). Women unlikely to require PMRT were randomised to either extended autologous LD (ALD) or implant-assisted LD breast reconstruction (LDI) (QUEST A), while those requiring PMRT were randomised to either immediate ALD or staged-delayed (two-stage skin preserving) ALD procedures (QUEST B) (Cancer Research UK, 2011). Trial development was embraced and informed by national collaborations involving oncoplastic breast surgeons, breast care nurses (BCNs), research nurses and patient advocacy groups. The separately funded (BUPA Foundation) QUEST Perspectives Study (QPS) was a nested qualitative study evaluating the perceptions of patients and HCPs on randomisation to inform trial processes and enhance ongoing recruitment and patient acceptability. QPS assessed patients' and HCPs' perceptions of equipoise and other aspects of the trial, including patients' perceptions of randomisation (Winters et al, 2011). QPS incorporated qualitative methods, and recruited patients both accepting or declining randomisation with the intention of assessing the impact of the decision-making process, so drawing on the lessons learnt from other feasibility studies such as the ProtecT (Prostate Testing for Cancer and Treatment) trial (Donovan et al, 2002). The primary objective of the QUEST feasibility phase was to demonstrate that the acceptance rate of randomisation was at least $25 \%$, with a target sample size of 55 patients to each of the QUEST A and B trials within 12 months. After 12 months of recruitment, 17 patients were randomised to QUEST A and 8 to QUEST B with overall randomisation acceptance rates of $19 \%(17 / 88)$ and $22 \%(8 / 36)$, respectively. Patient preference was the predominant reason for declining trial entry, affecting 47 of the 88 (53\%) patients approached for QUEST A and 22 of the 36 (61\%) approached for QUEST B. Despite extensive efforts by trial teams, both trials were closed to recruitment in December 2012 following recognition of the challenges of achieving satisfactory patient accrual and the limitation of feasibility funding.

An end-of-study survey completed by the centres indicated that only eight centres had sufficient throughput of LDI procedures during 2012 and only two centres were undertaking sufficient numbers of ALD reconstructions. Clearly, these changes in clinical practice would have prevented adequate patient accrual in the main trial regardless of patient preference issues (Millat et al, 2005). Technical advances in breast reconstruction using implantassisted acellular dermal matrices (ADMs) may have diminished the numbers of LD procedures being recommended (Winters and Colwell, 2014). However, it remains true that the main barriers to recruitment in QUEST were patient and clinician perceptions and preferences (Millat et al, 2005). Some centres indicated bias on the 
part of some plastic surgeons, with prejudice towards deep inferior epigastric artery perforator (DIEAP) flaps, particularly after PMRT. Furthermore, some plastic surgeons were biased about the concept of randomisation (QPS), possibly reflecting the surgeons' intolerance of 'uncertainty' (McCulloch et al, 2005).

The hierarchy of evidence places the meta-analyses of randomised controlled trials (RCTs) at the highest level for evaluating the effects of an intervention, although this rationale has recently been debated (Zuiderent-Jerak et al, 2012). Atkins et al (2004) emphasise the relevance of study design to the particular clinical question (Atkins et al, 2004). In a systematic review evaluating treatment questions, only $40 \%$ of hypotheses relating to surgical procedures were amenable to a randomisation design (McCulloch et al, 2002). The IDEAL Framework and Recommendations emerged from expert consensus consideration of this challenge (McCulloch et al, 2009). The Framework stresses the frequent need for preliminary studies before a surgical RCT can become a realistic prospect, and cites patient and surgeon preferences as one of the key factors that makes this so. Other factors relevant to the QUEST studies are also considered by IDEAL, particularly the effect of surgeon learning curves, the need for preliminary work to achieve real clinician consensus, and the need for measures of operative quality control. None of these factors impact significantly on most drug trials. Their prevalence in surgical trials mandates an approach to developing valid evidence for operations that directly addresses these unique problems.

Successful randomisation in surgical trials is straightforward where the stakes are low and the clinical community is either in genuine equipoise or largely favourable to the new treatment. Therefore simple trial designs predicated on basic surgical interventions like the ROSSINI trial (Pinkney et al, 2013), wound edge protection devices to prevent surgical site infection after laparotomy, and other simple yet beneficial surgical interventions such as skin flap fixation sutures (quilting) or tissue glue to reduce donor site seromas after breast reconstruction presented no challenges to patient recruitment and randomisation (Daltrey et al, 2006; Llewellyn-Bennett et al, 2012). However, where there is significant investment of 'professional capital' in learning and promoting a new technique, things are more difficult. New surgical techniques like acellular dermal matrix (ADM)-assisted implant breast reconstruction, however, pose challenges related to surgical learning curves, with doubling of surgical complications in the first 12 months of the surgeons' experiences compared to standard submuscular implant reconstructions (McCarthy et al, 2012). This is an issue that frequently frustrates efforts to perform an RCT, whereby the clinical community and patients often 'move on' accepting inferior evidence from observational studies to the extent that it can quickly become 'too late' to do an RCT, as appears to have happened with ADMs (McCarthy et al, 2012). Clearly, this phenomenon is very different from drug-related clinical trials where patients are often 'blinded' to their randomisation allocation (Barkun et al, 2009).

The QUEST feasibility trials showed that the major challenge to recruitment was patient preference (McCarthy et al, 2012). However, this begs the question about how these preferences arose. The provision of appropriate information based on patient values is a key element in achieving adequate recruitment in surgical trials (McCulloch et al, 2002). In QUEST, a trial process checklist was introduced to assist centres with informing patients of the treatment options and aid discussions about the trial. There were challenges in integrating these new communication processes within established patterns of clinical working at participating sites. However, centres where teams were strongly motivated by the trial aims adapted well to standardising information provision. QPS results highlighted the importance of identifying 'early' patient preferences, and of pro-active initiatives to ensure that patients are informed about the trial information (Winters et al, 2011). At
3 months into the trial, the introduction of the 'open access' policy to all women regardless of initially expressed preferences resulted in an increase in patient numbers approached and recruited. Furthermore, the principle that patients may 'shift their views' from expressing a strong preference to one of equipoise reduced the numbers of patients declining trial entry based on initial preference. The quarterly screening logs of randomisation acceptance rates increased from 14\% (1/7) (May to July 2011) to $33 \%$ (7/21) women (May to July 2012) in QUEST A. Likewise, QUEST B showed a similar rise in randomisation acceptance rates of $0 \%(0 / 2)$ (July to September 2011) to $38 \%$ (3/8) (July to September 2012).

Much has been learned from the landmark ProtecT trial, which aimed to compare three treatment arms (surgery, radiotherapy, and active monitoring) in men invited for prostate cancer screening within primary care (Donovan et al, 2002). Despite equivalent survival outcomes between treatments, randomisation had previously failed. Protect therefore used a nested trial of recruitment strategies, including nurse-led information on the rationale for the trial, to remove investigator bias from the information and consent process. Two randomisation pathways were permitted (three or two arm trials, respectively), and a patient preference arm was also agreed upon. ProtecT's qualitative research used audio recording of recruitment interviews and in-depth interviews to explore and balance communication on equivalence, including changing the order of presenting treatments. Exploratory studies on Corbett's seven descriptions of randomisation showed that the majority of clinicians 'dislike the emphasis given to chance' at such a stressful time (Jenkins et al, 2002). In ProtecT, recruiters needed to confidently express that men were eligible for all three treatments, of which the most effective was unknown, and that a trial was needed, with randomisation providing a plausible way of reaching a decision (Donovan et al, 2002). Removing the participating clinician from the information and consent process resulted in more patients being willing to be randomised.

The underlying message about the importance of both quantitative and qualitative research funded and timed to inform and change trial processes early on remains highly relevant to feasibility trials, as was shown in the Quartet (Qualitative research to improve recruitment to trials) study (de Salis et al, 2008). Perhaps the QUEST experience might have been different if the studies of patient and HCP perceptions had preceded the randomised feasibility studies, to identify potential barriers to recruitment and address them prior to recruitment commencing. As the ProtecT trial demonstrated, it is essential to develop tailored information to fully inform participants and address any concerns (Donovan et al, 2002). To overcome the preference problem in future, we need to consider alternative trial designs such as parallel preference arms and the 'cohort multiple randomised controlled trial' design (Relton et al, 2010). But we will also need to consider developing shared decision-making tools linked to analyses of large cohort and registry data helping patients to understand their treatment choices. In future, it is crucial to understand how to communicate the rationale for the trial so that potential participants understand the equipoise for treatment options and can appreciate how their participation may help others. Furthermore, the QPS shows the urgent need to address the public misunderstanding of randomisation.

\section{REFERENCES}

Atkins D, Best D, Briss PA, Eccles M, Falck-Ytter Y, Flottorp S, Guyatt GH, Harbour RT, Haugh MC, Henry D, Hill S, Jaeschke R, Leng G, Liberati A, Magrini N, Mason J, Middleton P, Mrukowicz J, O'connell D, Oxman AD, Phillips B, Schunemann HJ, Edejer T, Varonen H, Vist GE, Williams Jr JW, 
Zaza S (2004) Grading quality of evidence and strength of recommendations. BMJ 328: 1490.

Barkun JS, Aronson JK, Feldman LS, Maddern GJ, Strasberg SM, Altman DG, Barkun JS, Blazeby JM, Boutron IC, Campbell WB, Clavien PA, Cook JA, Ergina PL, Flum DR, Glasziou P, Marshall JC, Mcculloch P, Nicholl J, Reeves BC, Seiler CM, Meakins JL, Ashby D, Black N, Bunker J, Burton M, Campbell M, Chalkidou K, Chalmers I, de Leval M, Deeks J, Grant A, Gray M, Greenhalgh R, Jenicek M, Kehoe S, Lilford R, Littlejohns P, Loke Y, Madhock R, Mcpherson K, Rothwell P, Summerskill B, Taggart D, Tekkis P, Thompson M, Treasure T, Trohler U, Vandenbroucke J (2009) Evaluation and stages of surgical innovations. Lancet 374: 1089-1096.

Cancer Research UK (2011) Cancer Research UK - CRUK/08/027: QUEST: A multi-centre randomised trial to assess the impact of the type and timing of breast reconstruction on quality of life following mastectomy [Online]. Available at http://www.cancerresearchuk.org/cancer-help/trials/ a-trial-looking-how-women-feel-about-themselves-after-breastreconstruction-during-surgery-breast-cancerand http:// www.cancerresearchuk.org/cancer-help/trials/a-trial-comparing-howwomen-feel-about-themselves-after-having-immediate-or-delayedbreast-reconstruction-surgery-quest-b[accessed 12 June 2013].

Daltrey I, Thomson H, Hussien M, Krishna K, Rayter Z, Winters Z (2006) Randomized clinical trial of the effect of quilting latissimus dorsi flap donor site on seroma formation. Br J Surg 93: 825-830.

de Salis I, Tomlin Z, Toerien M, Donovan J (2008) Using qualitative research methods to improve recruitment to randomized controlled trials: the Quartet study. J Health Serv Res Policy 13: 92-96.

Donovan J, Mills N, Smith M, Brindle L, Jacoby A, Peters T, Frankel S, Neal D, Hamdy F (2002) Quality improvement report: Improving design and conduct of randomised trials by embedding them in qualitative research: ProtecT (prostate testing for cancer and treatment) study. Commentary: presenting unbiased information to patients can be difficult. BMJ 325: 766-770.

Jenkins V, Leach L, Fallowfield L, Nicholls K, Newsham A (2002) Describing randomisation: patients' and the public's preferences compared with clinicians' practice. $\mathrm{Br} J$ Cancer 87: 854-858.

Llewellyn-Bennett R, Greenwood R, Benson JR, English R, Turner J, Rayter Z, Winters ZE (2012) Randomized clinical trial on the effect of fibrin sealant on latissimus dorsi donor-site seroma formation after breast reconstruction. Br J Surg 99: 1381-1388.

McCarthy CM, Lee CN, Halvorson EG, Riedel E, Pusic AL, Mehrara BJ, Disa JJ (2012) The use of acellular dermal matrices in two-stage expander/ implant reconstruction: a multicenter, blinded, randomized controlled trial. Plast Reconstr Surg 130: 57S-66S.

mcculloch P, Altman DG, Campbell WB, Flum DR, Glasziou P, Marshall JC, Nicholl J, Aronson JK, Barkun JS, Blazeby JM, Boutron IC, Campbell WB, Clavien PA, Cook JA, Ergina PL, Feldman LS, Flum DR, Maddern GJ, Nicholl J, Reeves BC, Seiler CM, Strasberg SM, Meakins JL, Ashby D, Black N, Bunker J, Burton M, Campbell M, Chalkidou K, Chalmers I, de Leval M, Deeks J, Ergina PL, Grant A, Gray M, Greenhalgh R, Jenicek M, Kehoe S, Lilford R, Littlejohns P, Loke Y, Madhock R, Mcpherson K, Meakins J, Rothwell P, Summerskill B, Taggart D,
Tekkis P, Thompson M, Treasure T, Trohler U, Vandenbroucke J (2009) No surgical innovation without evaluation: the IDEAL recommendations. Lancet 374: 1105-1112.

Mcculloch P, Kaul A, Wagstaff GF, Wheatcroft J (2005) Tolerance of uncertainty, extroversion, neuroticism and attitudes to randomized controlled trials among surgeons and physicians. Br J Surg 92: 1293-1297.

Mcculloch P, Taylor I, Sasako M, Lovett B, Griffin D (2002) Randomised trials in surgery: problems and possible solutions. BMJ 324: 1448-1451.

Millat B, Borie F, Fingerhut A (2005) Patient's preference and randomization: new paradigm of evidence-based clinical research. World J Surg 29: 596-600.

Pinkney TD, Calvert M, Bartlett DC, Gheorghe A, Redman V, Dowswell G, Hawkins W, Mak T, Youssef H, Richardson C, Hornby S, Magill L, Haslop R, Wilson S, Morton D (2013) Impact of wound edge protection devices on surgical site infection after laparotomy: multicentre randomised controlled trial (ROSSINI Trial). BMJ 347: f4305.

Relton C, Torgerson D, O'cathain A, Nicholl J (2010) Rethinking pragmatic randomised controlled trials: introducing the 'cohort multiple randomised controlled trial' design. BMJ 340: c1066.

Schroen AT, Petroni GR, Wang H, Thielen MJ, Gray R, Benedetti J, Wang XF, Sargent DJ, Wickerham DL, Cronin W, Djulbegovic B, Slingluff JR CL (2012) Achieving sufficient accrual to address the primary endpoint in phase III clinical trials from U.S. Cooperative Oncology Groups. Clin Cancer Res 18: 256-262.

The NHS Information Centre - Clinical Effectiveness Unit at the Royal College of Surgeons (2011) National Mastectomy and Breast Reconstruction Audit 2011. [Online]. Fourth Annual ReportAvailable at http://www.ic.nhs.uk/services/[accessed 26 February 2013].

Winters Z, Mills J, Emson M, Bliss J, Horne R (2011) QUEST Perspective Study (QPS) to measure the understanding by patients and healthcare professionals of surgical breast reconstruction clinical trials. QUEST Trials A B 12(Suppl 1): A105.

Winters ZE, Benson JR, Pusic AL (2010) A systematic review of the clinical evidence to guide treatment recommendations in breast reconstruction based on patient- reported outcome measures and health-related quality of life. Ann Surg 252: 929-942.

Winters ZE, Colwell AS (2014) Role of acellular dermal matrix-assisted implants in breast reconstruction. Br J Surg 101: 444-445.

Winters ZE, Haviland J, Balta V, Benson J, Reece-Smith A, Betambeau N. The Prospective Trial Management, G (2013) Integration of patientreported outcome measures with key clinical outcomes after immediate latissimus dorsi breast reconstruction and adjuvant treatment. Br J Surg 100: $240-251$.

Zuiderent-Jerak T, Forland F, Macbeth F (2012) Guidelines should reflect all knowledge, not just clinical trials. BMJ 345: e6702.

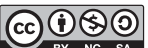

This work is licensed under the Creative Commons Attribution-NonCommercial-Share Alike 3.0 Unported License. To view a copy of this license, visit http://creativecommons. org/licenses/by-nc-sa/3.0/ 